\title{
General Science for Secondary Schools
}

$T$ HE science masters of Great Britain have hitched their wagon to a star; but, as men of science, they have selected the star with deliberate judgement and have satisfied themselves that the couplings are trustworthy. The interim report* on the teaching of general science just published by a sub-committee of the Science Masters' Association (after adoption by the general committee) is indeed characterized by the union of admirable ideals with sound good sense, and must be regarded as among the most weighty and most interesting of recent pronouncements on educational policy. There has long been on foot a movement to change the elementary part of the school science curriculum from its traditional, intensive and formal habit to a broader and more human shape ; to substitute, in fact, a scheme of 'general' science for the rudiments of one or two branches of academic science hitherto constituting the usual course followed by School Certificate candidates. The terms of reference of the subcommittee were as follow :

"To consider the problems presented to teachers in Secondary Schools by the introduction of courses in General Science as a constituent of general education, and to make specific suggestions about: 1. The aims to be kept in view. 2. The basic principles of the subject, an appreciation of which should be inculcated. 3 . The material to be included in such courses. 4. Methods of development and treatment of the material. 5. Timetable requirements at different stages."

The report (1) summarizes the growth of this movement from its inception in 1915-16 to the appointment of the present sub-committee in 1935 ; (2) considers the aims of science teaching; and (3) suggests and interprets a syllabus of general science, with a special note on the biological section.

It is natural to turn first to the committee's views upon the aims of science teaching, for the curriculum and treatment to be adopted must obviously depend upon the ultimate objective. The report observes that the numerous reasons urged to justify the inclusion of any subject in the school course can be roughly classified under the three headings of $(a)$ utilitarian or vocational, * The Teaching of General Science. Science Masters' Association
Interim Report of the Sub-Committee appointed in 1935. Adopted by the General Committee in 1936. (London: John Murray, 1936.) 28. $6 d$. net. (b) disciplinarian, and (c) cultural ; and the committee proceeds at once to make the important point that the preparation of technical experts cannot be considered as one of the functions of a school. We should have liked to see even greater emphasis given to this fundamental principle, which applies not only to the School Certificate stage but also to the two years afterwards spent in specialist studies by many boys and girls at school. We believe - and are confident that the vast majority of schoolmasters agree-that it ought to be no part of the business of a public or secondary school to train pupils for such professional examinations as the First M.B. The proper place for professional or technical training is the university or technical institution; and though parents may find it economical, and the university or institution convenient, to thrust a steadily increasing portion of such training upon the schools, the effect upon secondary education, already sufficiently serious, is likely in the long run to be extremely detrimental. On the other hand, the pre-preparation of experts is one of the schoolmaster's legitimate tasks, and, as the committee wisely remarks, "this can best be achieved by broadening the syllabus; for it is at school that particular talents are discovered and their development fostered. Many a potential specialist, in the life sciences especially, has been lost to the world by the narrowness of the teaching at school". The committee is too timid-or too polite- to add what should nevertheless be said in the plainest and most uncompromising English: that if the teaching at school is narrow, the fault is chiefly due to the stranglehold of the external examination system maintained by examining bodies under university control.

Vocational preparation, then, is relegated by the committee to a subordinate position, and this action is justified not merely on general grounds, but also because a purely vocational curriculum "presupposes a static, unchanging society" and because "the occupations of the people exhibit such amazing diversity that it is impossible to cater specifically for more than a small fraction". Where such a fraction is in practice catered for, the school authorities would do well to ask themselves whether they are not subsidizing some of their pupils at the expense of others. 
Upon the second claim advanced in favour of the teaching of science in schools; namely, that it develops "certain powers of clear and vigorous thinking, of coherent and logical deduction, of exact and accurate observation", the committee discreetly adopts an attitude of reserve, accepting -or at least not disputing--the experimental evidence "that the possibilities of transfer of training are much smaller than had formerly been supposed". It is, however, a little disconcerting to find that the committee next draws the quite unwarranted conclusion that school science syllabuses should not include "any matter whatever which is taught only for the sake of the training it gives". Dr. Arnold's remarks on such a capitulation would have been pleasurable hearing; but since it would probably be impossible to isolate any topic the value of which is purely disciplinary, the committee perhaps penned this sentence tongue in cheek. The committee is, on the contrary, wholly serious in its insistence upon the cultural aim of science teaching, urging that "the peculiar intellectual glory of the Western peoples has been the creation of a Natural Science which is far in advance of that of earlier times", and that no one "can now be considered truly cultured, no one can be considered as having felt the European spirit at its best, if he has never had his imagination stirred by that great adventure of ideas on which we are engaged: the scientific exploration of natural phenomena". These are noble sentiments finely expressed; they represent the true spirit in which science should be taught.

The committee feels that the cultural and subsidiary aims of science teaching may best be achieved by arranging courses in as liberal a manner as possible, and by designing them to cover a wide range; but it is not blind to the difficulties which general scienee has to encounter. The details of the practical problem have therefore been attacked with courage, with skill, and, we think, with a considerable degree of success. In constructing an 'ideal' syllabus the committee adopted three criteria: (I) the selected material should call forth activity on the part of the pupils, (2) every item in the syllabus should lead to the understanding of fundamental scientific principles, and (3) the syllabus should provide a field suited to the cultivation of those habits, interests and sentiments which are fundamental to science. For the systematic way in which these criteria were applied, and for the ingenious method employed to frame a scheme in which each criterion was fully respected, reference must be made to the report itself; but the syllabus as a whole is so constructed as to help the pupil toward an intelligent understanding of his immediate environment, his own body being the central figure in it.

A particularly welcome feature of the scheme is that the committee, all the members of which have had wide experience of science teaching, abandons the pursuit of "breaking down the barriers between the special sciences" (a phrase which the members admit to have puzzled them), and frankly observes that the division of science into three main branches is both convenient and logical. The syllabus is accordingly divided into three sections, dealing respectively with physics, biology and chemistry, but the lines of demarcation are not emphasized, and the root of each section lies in the common experience of average pupils. The time which the committee suggests as adequate for the course is 451 periods of 45 minutes plus 29 periods for revision, that is, a total of four periods a week for four school years. This allowance-which is accompanied on the syllabus-charts by suggestions as to the number of periods to be allotted to each individual topic-appears to be ample, and it is probable that sets of more intelligent pupils would be able to get through a good deal more than the printed course. If so, the additional material might suitably consist for the most part of chemistry, to which the committee has assigned only 95 of the 451 periods, as against 197 to physics and 159 to biology.

This reduction of the chemistry section of the syllabus is, we feel, the weakest part of the scheme, and the committee itself is apparently not here sure of its ground. No doubt the chemists of the Science Masters' Association will see to it that this one blemish in an excellent-and obviously workable-course of general science is removed before the interim report becomes the final report. In the meantime, Mr. J. A. Lauwerys (convener), Mr. C. L. Bryant (chairman) and all the members of the sub-committee must be congratulated upon having brought a most exacting task to a very satisfactory conclusion. They have shown that elementary science in our schools can be vastly improved, and, more than that, they have shown how the improvement may be effected. Since the main criticism of general science in the past has been that it is impracticable, the present report may become a landmark in the history of scientific education. 